\title{
The Relationship between Factors of Quality Models and Attributes of Process Models: Represented through Venn diagram
}

\author{
Basit Habib \\ Bahauddin Zakariya \\ University \\ Multan, Pakistan
}

\begin{abstract}
There are certain different software engineering tools which have been rapidly applied on various scenarios of Testing, Output, Relationship and other developing phases of any product. The Quality Models have the ability to implement their Factors and the Process Models can judge the requirements of any project in any phase of during its development. By synchronizing both of these main tools together, it can be easy for the developer to achieve the minimum requirements in a project to get the maximum out of it with having the surety of its working. The combination of these tools can form such a pattern which can be useful for the full functionality of a product to its development within the limitations.
\end{abstract}

\section{Keywords}

Venn diagram, Quality Factor, Quality Criterion, Process model attributes.

\section{INTRODUCTION}

This study is a combination of various Quality Models including McCall, Boehm, Dromey, and ISO 9126 [5]. From these models the Factors have been abstracted and against them there related Criterion. After this task the Attributes of various Process Models have been taken which include Perceptive, Waterfall, Incremental, Prototype, RAD, Spiral, win win Spiral, Concurrent Process Models[1]. In these models the attributes are taken and a relationship has been shown between the factors of the quality model Factors and there Attributes. For a better implementation and representation Venn Diagram is used so that the overlapping sequence can be judged properly [2][3].

\section{IMPLEMENTATION}

\subsection{Perceptive Model}

If universal set contains all the factors of McCall's ,Boehm's, dromey's and ISO 9126, The overlapping of five Attributes of perspective model with quality factors can be seen. In the below diagram,' C' denotes Communication,'P' denotes planning,' M' denotes

modeling,' c' (small c) denotes construction and 'D' denotes development. As a result, we will find above mentioned relationship of quality factors with components of perspective model[1][5].

Functionality,Reliability,Portability,Usability,Integrity,Testab ility,flexibility,Reusability,Interoperability,Human engineering and Understandability lies in CPDcD means all these factors lies in all five components of perspective model . Efficiency and maintainability lies in CPMD means that these two factors lie in communication, modeling, planning and development components of Perspective model[1][5].

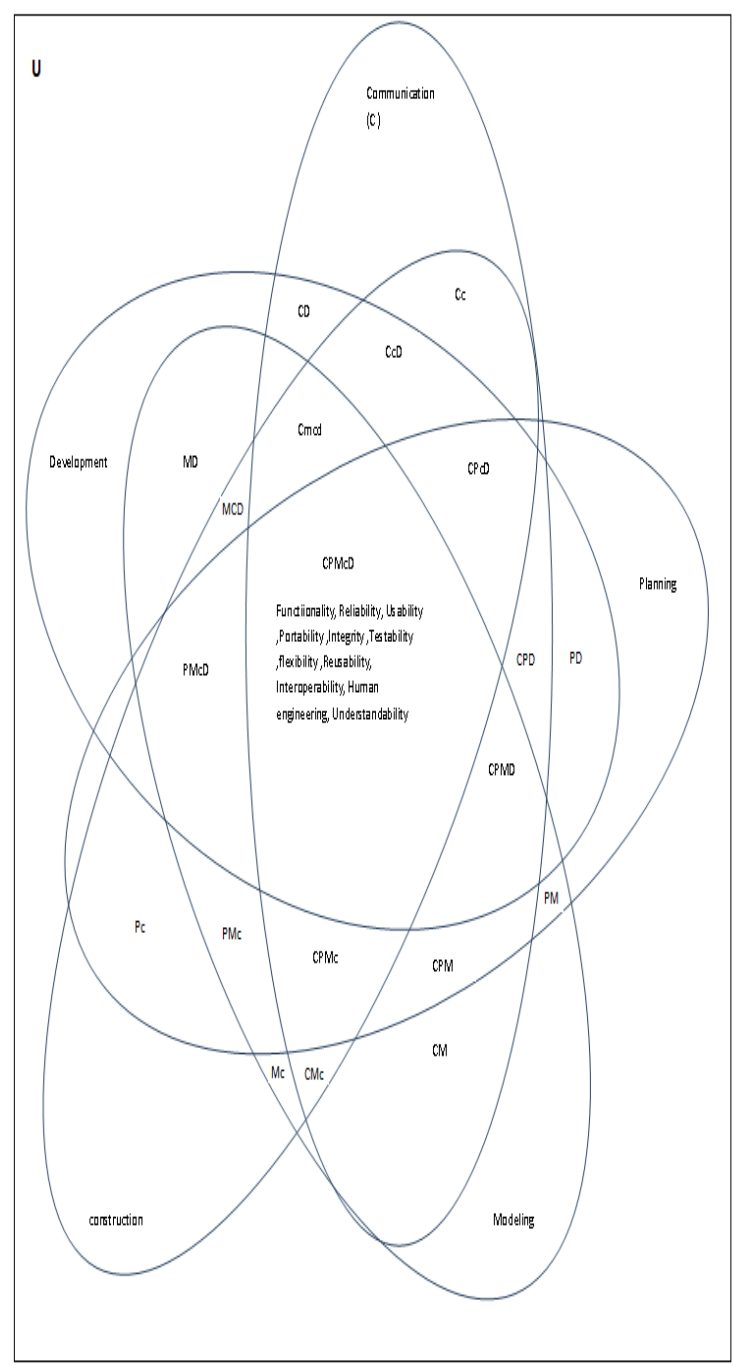

Fig 1: Perseptive model and Qaulity Factors 
Table1: Abbreviations regarding perceptive model

\begin{tabular}{|c|c|}
\hline \multicolumn{2}{|c|}{ Abbrivations } \\
\hline CO: Communiation, Develapment & PMc: Planning Modeling Cortutution \\
\hline CCO: Communiction, Construdion, Development & \\
\hline 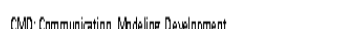 & CPM: Communiatition, Planning, \\
\hline 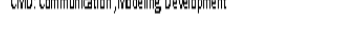 & Modeline \\
\hline CMC: Communiation, Modeling, Constrution, Development & PM:Planning, Modeling \\
\hline Mo: Modeling Cartitution, Development & Pcelanning Cartitution \\
\hline 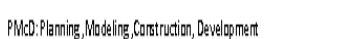 & CMc: Planning, Modeling, \\
\hline & Constrution) \\
\hline CPQ: Communiation, Planning, Corstutution, Development & Mc: Modeling, Corritudion) \\
\hline & :D: Cortutution,Develapment \\
\hline CPQ: Communiation, Planning, Corstrution, Development & \\
\hline CPD: Communication, Planning, Development & CD: Conmuniation, Developonnent \\
\hline CPMD: Communiction, Planning Modeling & PCD: Planning, Cortitudion, Developmentrt \\
\hline Development & PD:Planing Development \\
\hline Cecommuniation,construtionn & CPMc Communiction, Planning, \\
\hline & Modeling Corstrution \\
\hline
\end{tabular}

Table 2: occurrence of process models with software criterion

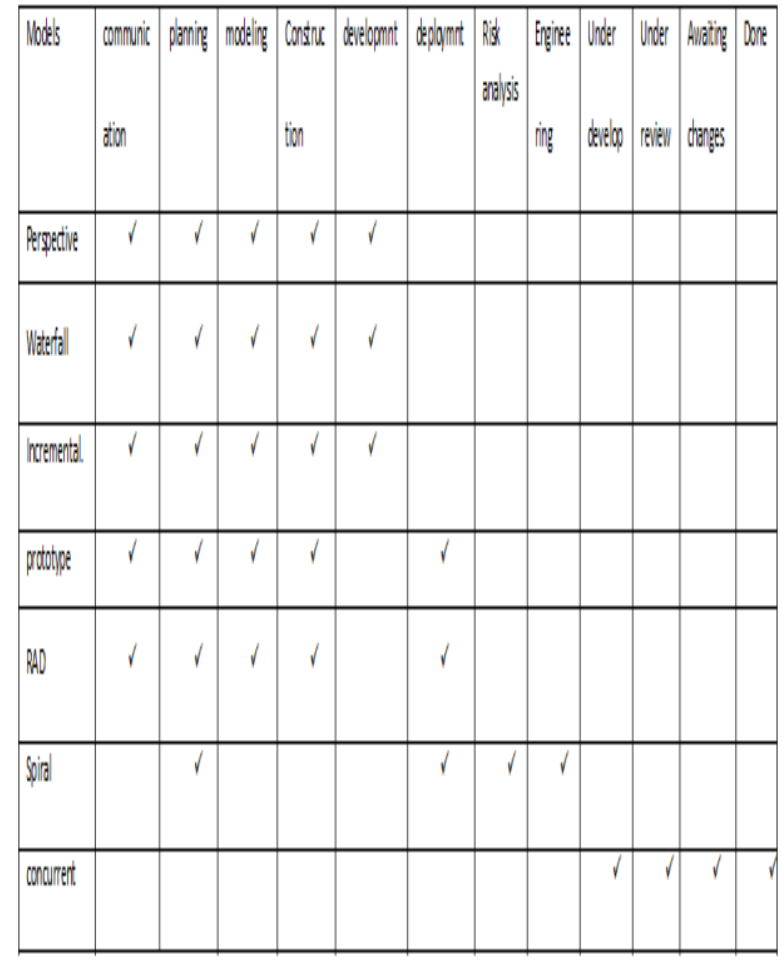

In Table 2: the list of all Process Models and their respective Criterion is discussed. In Perspective Model Communication, Planning, Modeling, Construction and Development components are present .In Waterfall Model communication, Modeling, Planning, construction and Development component are present. In Incremental process Model communication , Modeling, Planning, Construction and development components are present .In Prototype Model, Communication, Modeling, Planning, Construction and deployment are present .In RAD Model communication, Modeling, Planning, Construction and Deployment are present. In Spiral Model Planning, Deployment, Risk Analysis and Engineering components are present. In Concurrent Development Model Under development, Under Review, Awaiting Changes and Done components are present. In Unified Process Model Inception( Communication, Planning), Elaboration ( Planning ,Modeling) and Transition(Construction and Deployment ) components are present[1][5]

Table 3: McCals quality factors and process model

\begin{tabular}{|c|c|c|c|c|c|}
\hline Micall's: Qfators: & Communiction & planning & Modeling & constrution & develomertit \\
\hline Corretness & $\checkmark$ & $\gamma$ & t & r & V \\
\hline Reliability & $\checkmark$ & $\checkmark$ & r & $\checkmark$ & $\checkmark$ \\
\hline Efficiency & r & $\sqrt{ }$ & l & & f \\
\hline Integity & $\checkmark$ & $\checkmark$ & l & $\checkmark$ & $\checkmark$ \\
\hline Uablitty & $\sqrt{ }$ & $\sqrt{ }$ & 7 & r & $\gamma$ \\
\hline \begin{tabular}{|l|l|} 
Maintainabilty \\
\end{tabular} & t & $\sqrt{r}$ & 7 & & ᄀ \\
\hline Tetability & $\checkmark$ & $\checkmark$ & l & $\checkmark$ & $\checkmark$ \\
\hline Flexibility & r & $\sqrt{ }$ & 7 & V & V \\
\hline Potability & $\checkmark$ & $\checkmark$ & l & $\checkmark$ & $\checkmark$ \\
\hline Reuability & $\checkmark$ & $\sqrt{ }$ & l & $\checkmark$ & $\checkmark$ \\
\hline
\end{tabular}

In table 3: the list of all factors of Mac Calls Quality Model and also their Occurrence in five component i.e Communication ,Planning, Modeling , and development component of Perspective Model is discussed .The first factor Correctness is found in Communication, Modeling, Planning ,Construction and Development .The Second factor Reliability is found in Communication, Modeling, Planning ,Construction and Development component of Perspective Model .The third factor Efficiency is found in Communication, Modeling, Planning and Development component of Perspective Model. The fourth factor Integrity is found in Communication, Modeling, Planning, Construction and Development component of Perspective Model. The fifth factor Usability is found in Communication, Modeling, Planning, Construction and Development Component of Perspective Model. The sixth factor Maintainability $\mathrm{s}$ found in Communication, Planning, Modeling and development component of Perspective Model. The seventh factor Testability is found in Communication, Planning, Modeling, Construction and development component of Perspective Model. The eighth factor Flexibility is found in Communication, Modeling, Planning, Construction and development factor of Perspective Model .The ninth factor Portability is found in communication, Modeling, Planning, Construction and Development component of Perspective Model. The tenth factor Reusability is found in Communication, Planning, Modeling, Construction and Development components of Perspective Model [1][5]. 
Table 4: Boehm quality factors and process model

\begin{tabular}{|c|c|c|c|c|c|}
\hline Boenm'sQ fortors & Comminiction & Nodeing & paning & constution & dereconent \\
\hline Pritaility & v & t & 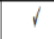 & $\sqrt{ }$ & V \\
\hline Relatily & v & $r$ & $\checkmark$ & v & v \\
\hline efficenoy & $\checkmark$ & $\checkmark$ & $\checkmark$ & & $\checkmark$ \\
\hline Humal Egginetring & $\sqrt{ }$ & $\frac{1}{1}$ & 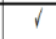 & t & V \\
\hline Testablity & r & $\checkmark$ & $\checkmark$ & l & $\checkmark$ \\
\hline Understandositity & $\sqrt{1}$ & $\sqrt{ }$ & r & t & v \\
\hline
\end{tabular}

In table 4: the list of all factors of Boehm's Quality Model and also their Occurrence in five component i.e Communication ,Planning ,Modeling , and Development component of Perspective Model is discussed .The first factor Portability is found in Communication, Modeling, Planning ,Construction and Development .The Second factor Reliability is found in Communication, Modeling, Planning ,Construction and Development component of Perspective model .The third factor Efficiency is found in Communication, Modeling, Planning and Development component of Perspective Model. The fourth factor Human Engineering is found in Communication, Modeling, Planning, Construction and Development component of Perspective Model. The fifth factor Testability is found in Communication, Modeling, Planning, Construction and Development Component of Perspective Model. The sixth factor Understandability is found in Communication, Planning, Modeling and development component of Perspective Model[1][5].

Table 5: Dromey quality factors and process model

\begin{tabular}{|c|c|c|c|c|c|}
\hline $\begin{array}{l}\text { Dromeys Q fifctors } \\
\text { Funtionalty }\end{array}$ & $\begin{array}{c}\text { Communication } \\
\checkmark\end{array}$ & $\begin{array}{c}\text { Modeing } \\
r\end{array}$ & $\begin{array}{c}\text { Planing } \\
\text { / }\end{array}$ & $\begin{array}{c}\text { Consinution } \\
\gamma\end{array}$ & $\begin{array}{c}\text { Development } \\
\gamma\end{array}$ \\
\hline Reliabiliy & V & r & 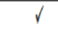 & V & V \\
\hline Maintaninability & V & r & $r$ & & $\checkmark$ \\
\hline Efficiency & $\checkmark$ & r & $r$ & & $\checkmark$ \\
\hline Relsability & V & $\sqrt{1}$ & 1 & $r$ & v \\
\hline Pottabilty & $\gamma$ & r & r & r & $\checkmark$ \\
\hline Usbility & r & r & r & $\checkmark$ & $\sqrt{ }$ \\
\hline
\end{tabular}

In table 5: the list of all factors of Dromey's Quality Model and also their Occurrence in five component i.e Communication ,Planning ,Modeling, construction and Development component of Perspective Model is discussed .The first factor Functionality is found in Communication, Modeling, Planning, Construction and Development .The Second factor Reliability is found in Communication,
Modeling, Planning ,Construction and Development component of Perspective model .The third factor Maintainability is found in Communication, Modeling, Planning and Development component of Perspective Model. The fourth factor Efficiency is found in Communication, Modeling, Planning and Development component of Perspective Model. The fifth factor Reusability is found in Communication, Modeling, Planning, Construction and Development Component of Perspective Model. The sixth factor portability is found in Communication, Planning, Modeling and development component of Perspective Model .The seventh factors Usability is found in Communication, Planning, Modeling ,Construction and Development Component of Perspective Model[1][5]

Table 5: ISO quality factors and process model

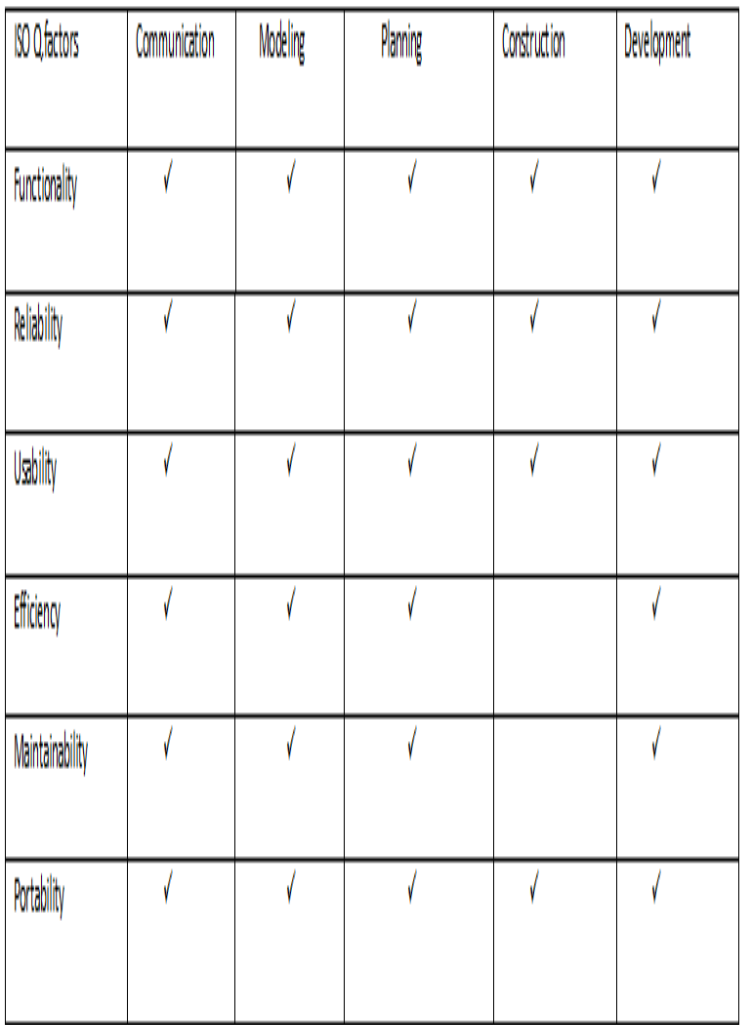

In table5: the list of all factors of ISO Quality Model and also their Occurrence in five component i.e Communication, Planning, Modeling ,Construction and development component of Perspective Model is discussed .The first factor Functionality is found in Communication, Modeling, Planning ,Construction and Development .The Second factor Reliability is found in Communication, Modeling, Planning ,Construction and Development component of Perspective model .The third factor Usability is found in Communication, Modeling, Planning and Development component of Perspective Model. The fourth factor Efficiency is found in Communication, Modeling, Planning and Development component of Perspective Model. The fifth factor Maintainability is found in Communication, Modeling, Planning and Development Component of Perspective Model. The sixth factor portability is found in Communication, Planning, Modeling and development component of Perspective Model [1][5]. 


\subsection{Water Fall Model}

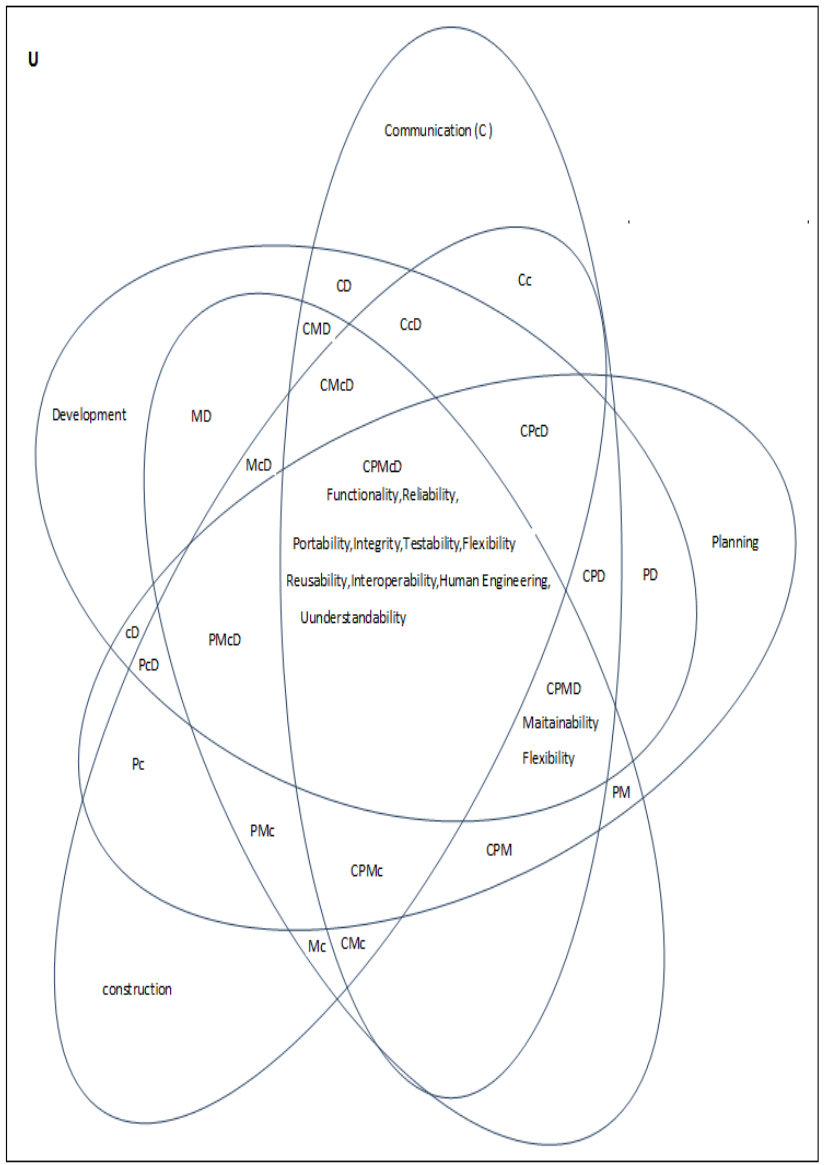

Fig 2: Water fall Model with quality Factors

Table 7: Abbreviations of Waterfall model with quality models

\begin{tabular}{|c|c|}
\hline \multicolumn{2}{|c|}{ Abbrivations } \\
\hline 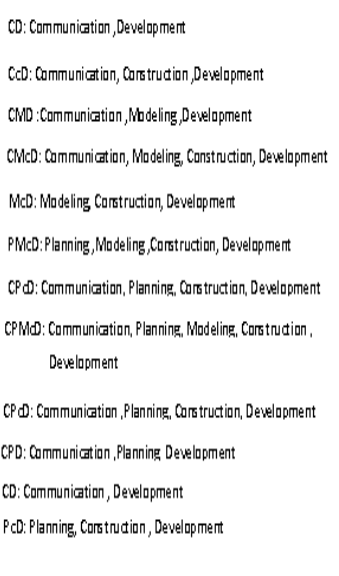 & 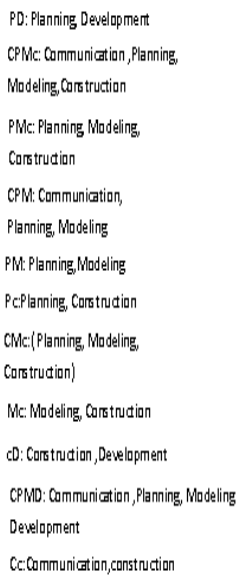 \\
\hline
\end{tabular}

In this Venn diagram, Our universal set contains all the factors of McCall's ,Boehm's, Dromey's and ISO .The overlapping of five Components of waterfall model with quality factors of McCall's ,Boehm's, Dromey's and ISO is shown .In this diagram $\mathrm{C}$ denotes Communication, $\mathrm{P}$ denotes planning , $\mathrm{M}$ denotes modeling, $\mathrm{c}$ denotes construction and $\mathrm{D}$ denotes development .As a result, we have find above mentioned relationship of quality factors with components of
waterfallmodelfunctionality,Reliability,Portability,Usability,I ntegrity,Testability,flexibility,Reusability,Interoperability,Hu man engineering and Understandability lies in CPDcD means all these factors lies in all five components of waterfall model. while efficiency and maintainability lies in CPMD means that these two factors lies in Communication ,modeling, planning and development components of Waterfall model[1][5]

Table 8: Occurrence of quality Criterion with Waterfall Model

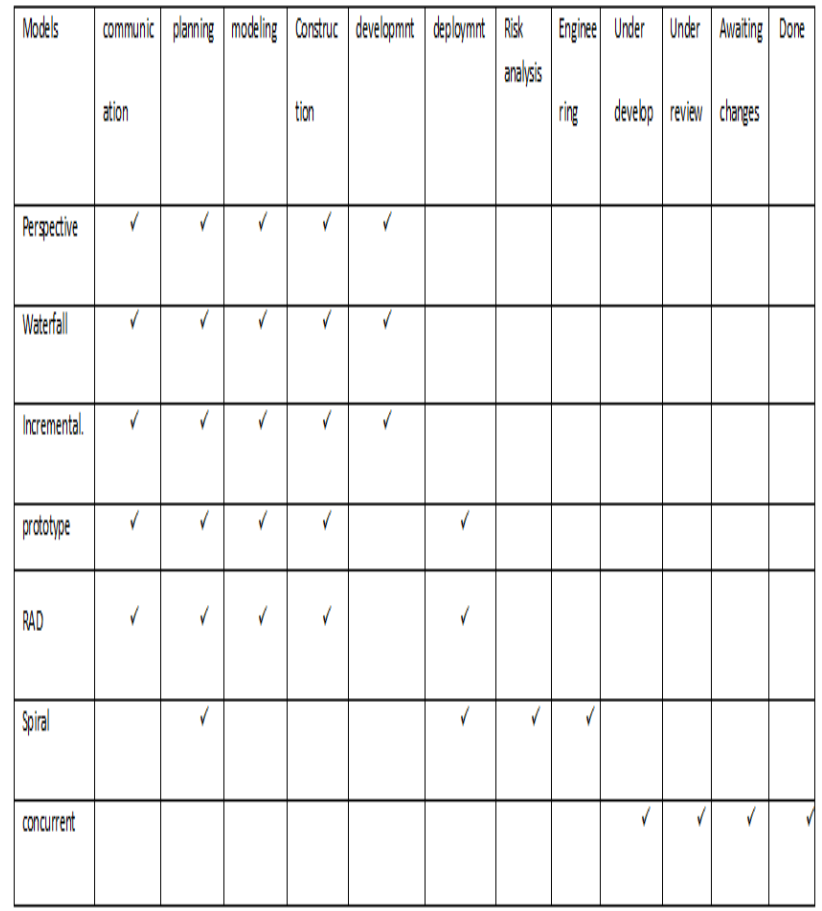

In Table 8 : the list of all Process Models and their respective Criterion is discussed .In Perspective Model Communication, Planning, Modeling, Construction and Development component are present .In Waterfall Model communication ,Modeling, Planning, construction and Development component are present. In Incremental process Model Communication, Modeling, Planning, Construction and development components are present. In Prototype Model, Communication, Modeling, Planning, Construction and deployment are present .In RAD Model communication, Modeling, Planning, Construction and Development are present. In Spiral Model Planning, Deployment, Risk Analysis and Engineering components are present. In Concurrent Development Model Under development, Under Review, Awaiting Changes and Done components are present. In Unified Process Model Inception( Communication, Planning),Elaboration( Planning ,Modeling) and Transition(Construction and Deployment ) components are present[1][5]. 
Table 9: McCall quality factors and Waterfall model

\begin{tabular}{|c|c|c|c|c|c|}
\hline MeCcall's Q f,atcors & communication & plaming & Mbdelirg & Constnuction & \begin{tabular}{|l} 
development \\
\end{tabular} \\
\hline corredness & s & $\checkmark$ & 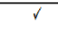 & a & $\checkmark$ \\
\hline Reliability & 8 & 8 & 8 & 8 & 8 \\
\hline Efficiency & $\checkmark$ & $\checkmark$ & $\checkmark$ & & r \\
\hline integity & 8 & $\checkmark$ & $\checkmark$ & 8 & $\checkmark$ \\
\hline Usability & r & $\checkmark$ & $\checkmark$ & $\checkmark$ & r \\
\hline Maintainabality & 8 & $\checkmark$ & 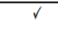 & & $r$ \\
\hline \begin{tabular}{|l} 
Testability \\
\end{tabular} & 7 & 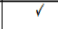 & 7 & 7 & $r$ \\
\hline Flexibility & $\checkmark$ & $\checkmark$ & $\checkmark$ & s & r \\
\hline portability & 8 & $\checkmark$ & $\checkmark$ & 8 & $\checkmark$ \\
\hline Reuability & r & $\checkmark$ & $\checkmark$ & r & $\checkmark$ \\
\hline
\end{tabular}

In table 9: the list of all factors of McCall's Quality Model and also their Occurrence in five component i.e Communication ,Planning, Modeling , and development component of Waterfall Model is discussed .The first factor Correctness is found in Communication, Modeling, Planning ,Construction and Development .The Second factor Reliability is found in Communication, Modeling, Planning ,Construction and Development component of Waterfall model .The third factor Efficiency is found in Communication, Modeling, Planning and Development component of Waterfall Model. The fourth factor Integrity is found in Communication, Modeling, Planning , Construction and Development component of Waterfall model. The fifth factor Usability is found in Communication, Modeling, Planning, Construction and Development Component of Waterfall Model. The sixth factor Maintainability s found in Communication, Planning, Modeling and development component of Waterfall Model. The seventh factor Testability is found in Communication, Planning, Modeling, Construction and development component of Waterfall Model. The eighth factor Flexibility is found in Communication, Modeling, Planning, Construction and development factor of Waterfall Model .The ninth factor Portability is found in Communication, Modeling, Planning, Construction and Development component of Waterfall Model. The tenth factor Reusability is found Communication, Modeling , Planning, Construction and Development components of Waterfall Model[1][5].

Table 10: Boehm quality factors and Waterfall model

\begin{tabular}{|l|c|c|c|c|c|}
\hline 'Boehm's Q fatators & Communication & Modeling & planning & consruction & development \\
\hline portability & $\checkmark$ & $\checkmark$ & $\checkmark$ & $\checkmark$ & $\checkmark$ \\
\hline reliability & $\checkmark$ & $\checkmark$ & $\checkmark$ & $\checkmark$ & $\checkmark$ \\
\hline eficiciency & $\checkmark$ & $\checkmark$ & $\checkmark$ & & $\checkmark$ \\
\hline Human Enginering & $\checkmark$ & $\checkmark$ & $\checkmark$ & $\checkmark$ & $\checkmark$ \\
\hline Testability & $\checkmark$ & $\checkmark$ & $\checkmark$ & $\checkmark$ & $\checkmark$ \\
\hline Understandabitity & $\checkmark$ & $\checkmark$ & $\checkmark$ & $\checkmark$ & $\checkmark$ \\
\hline
\end{tabular}

In table10: the list of all factors of Boehm's Quality Model and also their Occurrence in five component i.e Communication ,Planning ,Modeling ,and Development component of Waterfall Model is discussed .The first factor Portability is found in Communication, Modeling, Planning ,Construction and Development .The Second factor Reliability is found in Communication, Modeling, Planning ,Construction and Development component of Waterfall model .The third factor Efficiency is found in Communication, Modeling, Planning and Development component of Waterfall Model. The fourth factor Human Engineering is found in Communication, Modeling, Planning, Construction and Development component of waterfall model. The fifth factor Testability is found in Communication, Modeling, Planning, Construction and Development Component of waterfall Model. The sixth factor Understandability is found in Communication, Planning, Modeling and development component of Waterfall Model [1][5].

\section{Table 11: Dromey quality factors and Waterfall model}

\begin{tabular}{|l|c|c|c|c|c|}
\hline Dromey's Q,factors & Communication & Modeling & Planning & Construction & Development \\
Functionality & $\checkmark$ & $\checkmark$ & $\checkmark$ & $\checkmark$ & $\checkmark$ \\
\hline Reliability & $\checkmark$ & $\checkmark$ & $\checkmark$ & $\checkmark$ & $\checkmark$ \\
\hline Maintainability & $\checkmark$ & $\checkmark$ & $\checkmark$ & & $\checkmark$ \\
\hline Efficiency & $\checkmark$ & $\checkmark$ & $\checkmark$ & & $\checkmark$ \\
\hline Reusability & $\checkmark$ & $\checkmark$ & $\checkmark$ & $\checkmark$ & $\checkmark$ \\
\hline Portabilty & $\checkmark$ & $\checkmark$ & $\checkmark$ & $\checkmark$ & $\checkmark$ \\
\hline Ussbility & $\checkmark$ & $\checkmark$ & $\checkmark$ & $\checkmark$ & $\checkmark$ \\
\hline
\end{tabular}

In table11: the list of all factors of Dromey's Quality Model and also their Occurrence in five component i.e Communication ,Planning ,Modeling, construction and Development component of Waterfall Model is discussed .The first factor Functionality is found in Communication, Modeling, Planning ,Construction and Development .The Second factor Reliability is found in Communication, Modeling, Planning ,Construction and Development component of Waterfall model .The third factor Maintainability is found in Communication, Modeling, Planning and Development component of Waterfall Model. The fourth factor Efficiency is found in Communication, Modeling, Planning and Development component of Waterfall model. The fifth factor Reusability is found in Communication, Modeling, Planning, Construction and Development Component of Waterfall Model. The sixth factor portability is found in Communication, Planning, Modeling and development component of Waterfall Model .The seventh factors Usability is found in Communication, Planning, Modeling ,Construction and Development Component of Waterfall Model[1][5]. 
Table 12: ISO quality factors and Waterfall model

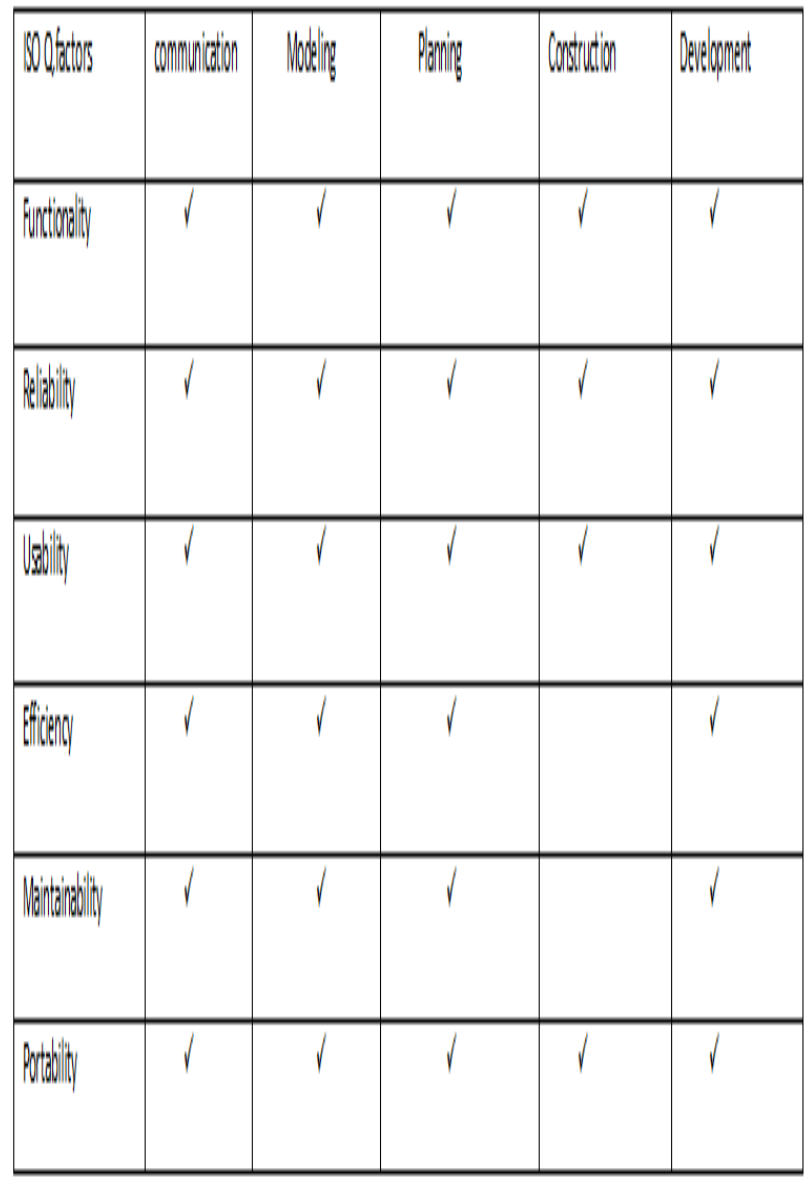

In table12: the list of all factors of ISO Quality Model and also their Occurrence in five component i.e Communication, Planning, Modeling ,Construction and development component of Waterfall Model is discussed .The first factor Functionality is found in Communication, Modeling, Planning ,Construction and Development .The Second factor Reliability is found in Communication, Modeling, Planning ,Construction and Development component of Waterfall model .The third factor Usability is found in Communication, Modeling, Planning and Development component of Waterfall Model. The fourth factor Efficiency is found in Communication, Modeling ,Planning and Development component of waterfall model. The fifth factor Maintainability is found in Communication , Modeling, Planning and Development Component of waterfall Model. The sixth factor portability is found in Communication ,Planning, Modeling and development component of Waterfall Model[1][5].

\subsection{Incremental Model}

Fig 3: incremental model and software quality Factors

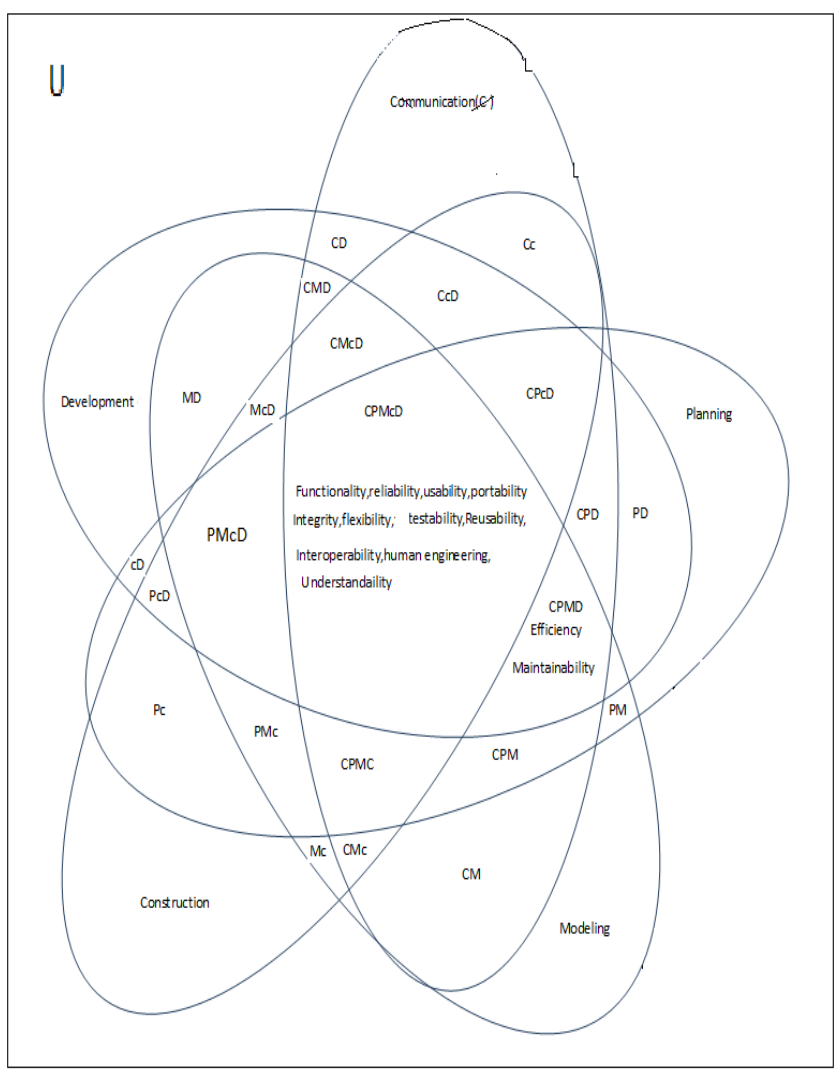

Table 13: abbreviations of quality factors and Incremental Model

\begin{tabular}{|c|c|}
\hline \multicolumn{2}{|c|}{ Abbrivations } \\
\hline 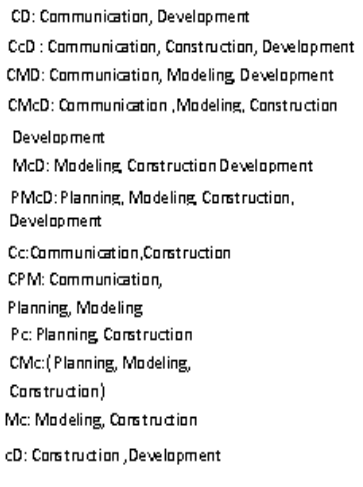 & 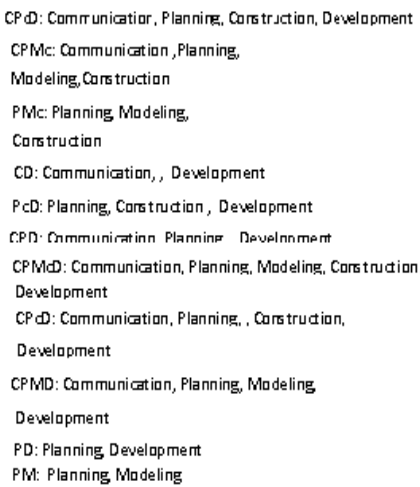 \\
\hline
\end{tabular}

In this set theory diagram, Our universal set contains all the factors of McCall's ,Boehm's, dromey's and ISO .The overlapping of five Components of Incremental process model with quality factors of McCall's, Boehm's, dromey's and ISO is shown .In this diagram $\mathrm{C}$ denotes Communication, $\mathrm{P}$ denotes planning, $\mathrm{M}$ denotes modeling, $\mathrm{c}$ denotes construction and $\mathrm{D}$ denotes development. As a result, we have find above mentioned relationship of quality factors with components of Incremental process model functionality,Reliability,Portability,Usability,Integrity,Testabi lity,flexibility,Reusability,Interoperability,Human engineering and Understandability lies in CPDcD means all these factors lies in all five components of Incremental process model. 
while efficiency and maintainability lies in CPMD means that these two factors lies in Communication ,modeling, planning and development components of Incremental process model[1][5].

Table 14: Software quality Criterion and Incremental Model

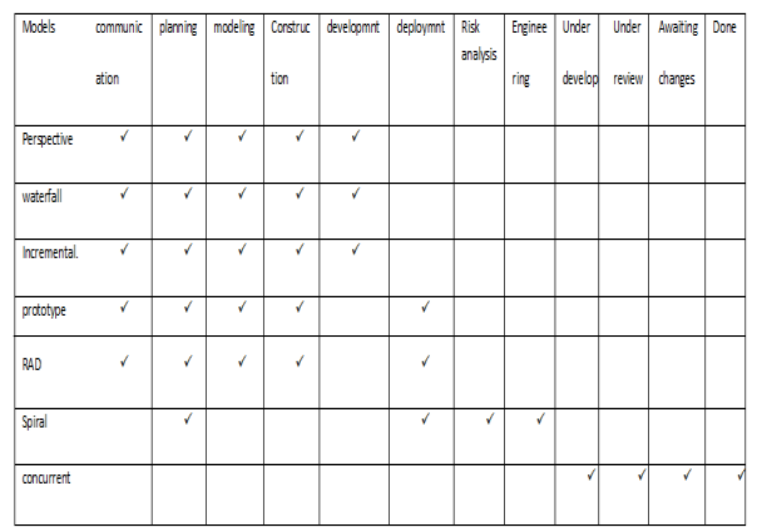

In Table 14 : the list of all Process Models and their respective Criterion is discussed. In Perspective Model Communication, Planning, Modeling, Construction and Development component are present .In Waterfall Model communication ,Modeling, Planning, construction and Development component are present. In Incremental process Model communication, Modeling, Planning, Construction and development components are present. In Prototype Model, Communication, Modeling, Planning, Construction and deployment are present .In RAD Model communication, Modeling, Planning, Construction and Development are present. In Spiral Model Planning, , Risk Analysis ,Engineering and Deployment components are present. In Concurrent Development Model Under development, Under Review , Awaiting Changes and Done components are present. In Unified Process Model Inception( Communication, Planning), Elaboration( Planning ,Modeling) and Transition(Construction and Deployment ) components are present[1][5].

Table 15: McCall quality Model and Incremental Model

\begin{tabular}{|c|c|c|c|c|c|}
\hline Maccal/s Qfodters & communiction & plaming & Modeling & consturtion & develomement \\
\hline corretness & $\mathrm{d}$ & $\frac{9}{2}$ & 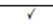 & 8 & 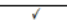 \\
\hline Reliability & $\checkmark$ & $\checkmark$ & $\checkmark$ & $\checkmark$ & $\checkmark$ \\
\hline Efficténgy & $\checkmark$ & 2 & $\checkmark$ & & $\checkmark$ \\
\hline integrity & $\checkmark$ & $\checkmark$ & $\checkmark$ & $\checkmark$ & $\checkmark$ \\
\hline Usbobity & $\checkmark$ & $\mathrm{r}$ & $v^{2}$ & 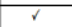 & $\checkmark$ \\
\hline Maintanability & $\mathrm{v}$ & 2 & 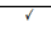 & & $\bar{v}$ \\
\hline Testabilty & $\mathrm{d}$ & $\frac{2}{2}$ & $\frac{9}{2}$ & 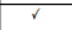 & 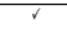 \\
\hline feribility & $\mathrm{a}$ & $\mathrm{r}$ & 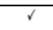 & $\mathrm{r}$ & $d$ \\
\hline portablity & $\checkmark$ & 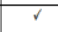 & $r^{2}$ & $\mathrm{r}$ & $\mathrm{d}$ \\
\hline Pevability & $\mathrm{d}$ & $v^{2}$ & $r^{2}$ & $\frac{1}{4}$ & $a^{2}$ \\
\hline
\end{tabular}

In table 15: the list of all factors of MacCall's Quality Model and also their Occurrence in five component i.e Communication ,Planning, Modeling , and development component of Incremental Process Model is discussed.The first factor Correctness is found in Communication, Modeling, Planning ,Construction and Development .The Second factor Reliability is found in Communication, Modeling, Planning
,Construction and Development component of Incremental Process Model .The third factor Efficiency is found in Communication, Modeling, Planning and Development component of Incremental Process Model. The fourth factor Integrity is found in Communication, Modeling ,Planning, Construction and Development component of Incremental Process Model. The fifth factor Usability is found in Communication , Modeling, Planning, Construction and Development Component of Incremental Process Model. The sixth factor Maintainability $\mathrm{s}$ found in Communication, Planning, Modeling and development component of Incremental Process Model. The seventh factor Testability is found in Communication, Planning, Modeling, Construction and development component of Incremental Process Model. The eighth factor Flexibility is found in Communication , Modeling, Planning, Construction and development Components of Incremental Process Model .The ninth factor Portability is found in communication, Modeling, Planning, Construction and Development component of Incremental Process Model .The tenth factor Reusability is found in Communication, Modeling , Planning, Construction and Development component of Incremental Process Model[1][5].

Table 16: Boehm Model Quality and Incremental Model

\begin{tabular}{|c|c|c|c|c|c|}
\hline 'Boeth's Q fatcors & communiction & Modeling & planning & consrution & development: \\
\hline portability & $\checkmark$ & $\checkmark$ & $\sqrt{1}$ & $\checkmark$ & $\checkmark$ \\
\hline reliability & v & v & $\sqrt{ }$ & v & v \\
\hline efficiency & V & v & V & & V \\
\hline Human Engineering & V & v & V & V & V \\
\hline Testability & v & v & v & $\bar{v}$ & $\sqrt{ }$ \\
\hline Understandoitiy & $\checkmark$ & v & $\sqrt{ }$ & $\bar{v}$ & $\bar{v}$ \\
\hline
\end{tabular}

In table 16: the list of all factors of Boehm's Quality Model and also their Occurrence in five component i.e Communication ,Planning ,Modeling ,and Development component of Incremental Process Model is discussed .The first factor Portability is found in Communication, Modeling, Planning ,Construction and Development .The Second factor Reliability is found in Communication, Modeling, Planning ,Construction and Development component of Incremental Process Model .The third factor Efficiency is found in Communication, Modeling, Planning and Development component of Incremental Process Model. The fourth factor Human Engineering is found in Communication, Modeling, Planning, Construction and Development component of Incremental Process Model. The fifth factor Testability is found in Communication, Modeling, Planning, Construction and Development Component of Incremental Process Model. The sixth factor Understandability is found in Communication, Planning, Modeling and development component of Incremental Process Model [1][5]. 
Table 17: Dromeys Quality and Incremental Model

\begin{tabular}{|c|c|c|c|c|c|}
\hline Dromy's Qfatoros & Communication & Modeling & Planing & Constrution & Development \\
\hline Functionality & $\checkmark$ & $\checkmark$ & $\checkmark$ & $\checkmark$ & 1 \\
\hline Relibality & $\checkmark$ & $\checkmark$ & $\checkmark$ & $\checkmark$ & 7 \\
\hline Maintzinability & r & $\checkmark$ & $\checkmark$ & & l \\
\hline Eficienny & 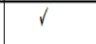 & 7 & r & & 7 \\
\hline Reussobility & $\checkmark$ & $\checkmark$ & $\checkmark$ & $\checkmark$ & l \\
\hline Portability & r & $r$ & $\checkmark$ & $\checkmark$ & 1 \\
\hline Usablity & V & l & $\gamma$ & V & 7 \\
\hline
\end{tabular}

In table 17: the list of all factors of Dromey's Quality Model and also their Occurrence in five component i.e Communication ,Planning ,Modeling, construction and Development component of Incremental Process Model is discussed .The first factor Functionality is found in Communication, Modeling, Planning ,Construction and Development .The Second factor Reliability is found in Communication, Modeling, Planning ,Construction and Development component of Incremental Process Model .The third factor Maintainability is found in Communication, Modeling, Planning and Development component of Incremental Process Model. The fourth factor Efficiency is found in Communication, Modeling , Planning and Development component of Incremental Process Model. The fifth factor Reusability is found in Communication, Modeling, Planning, Construction and Development Component of Incremental Process Model. The sixth factor portability is found in Communication, Planning, Modeling and development component of Incremental Process Model .The seventh factors Usability is found in Communication, Planning, Modeling ,Construction and Development Component of incremental Process Model[1][5].

Table 18: ISO Quality and Incremental Model

\begin{tabular}{|c|c|c|c|c|c|}
\hline 180 Q factors & Communiction & Nodeling & Plaming & Constrution & Developmentit \\
\hline Functional'ty & V & $\sqrt{1}$ & v & V & V \\
\hline Relibility & 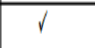 & $\sqrt{1}$ & V & 7 & $\sqrt{ }$ \\
\hline Usbolity & $\checkmark$ & $\checkmark$ & v & v & v \\
\hline Efficency & $\checkmark$ & $\sqrt{ }$ & $\checkmark$ & & 1 \\
\hline Maintinainoilyy & v & $\checkmark$ & v & & v \\
\hline Portidility & $\bar{v}$ & v & $\bar{v}$ & $\overline{1}$ & $\bar{V}$ \\
\hline
\end{tabular}

In table 18: the list of all factors of ISO Quality Model and also their Occurrence in five component i.e Communication, Planning, Modeling ,Construction and development component of Incremental Process Model is discussed .The first factor Functionality is found in Communication, Modeling, Planning ,Construction and Development .The Second factor Reliability is found in Communication, Modeling, Planning ,Construction and Development component of Incremental Process Model .The third factor Usability is found in Communication, Modeling, Planning and Development component of Incremental Process Model. The fourth factor Efficiency is found in Communication, Modeling, Planning and Development component of Incremental Process Model. The fifth factor Maintainability is found in Communication , Modeling, Planning and Development Component of incremental Process Model. The sixth factor portability is found in Communication, Planning, Modeling and development component of Incremental Process Model[1][5].

\subsection{Rapid Access Development Model}

Fig 4: RAD and Quality Factors

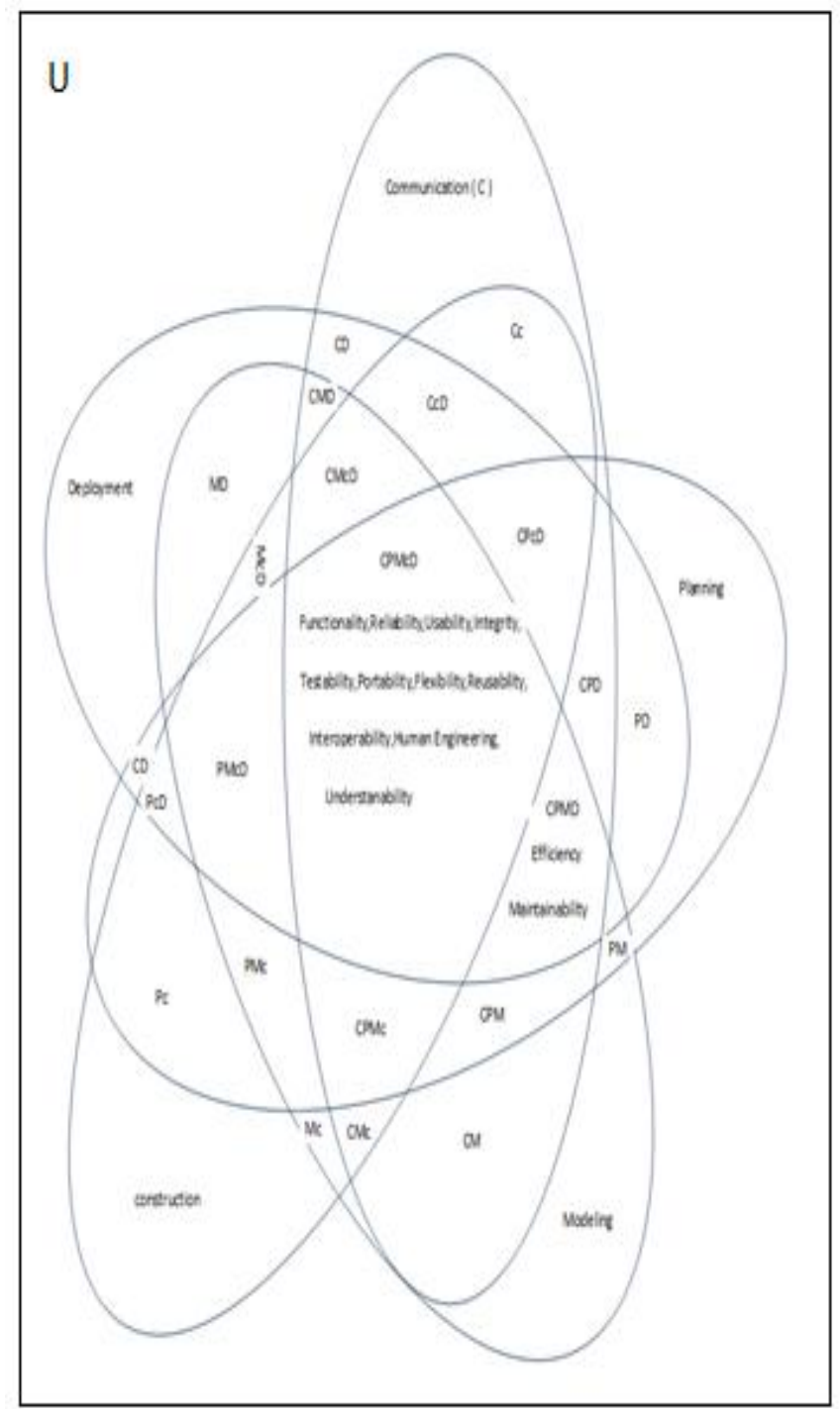


Table 19: Abbreviations of RAD and quality Models

\begin{tabular}{|c|c|}
\hline \multicolumn{2}{|c|}{ Abbrivations } \\
\hline 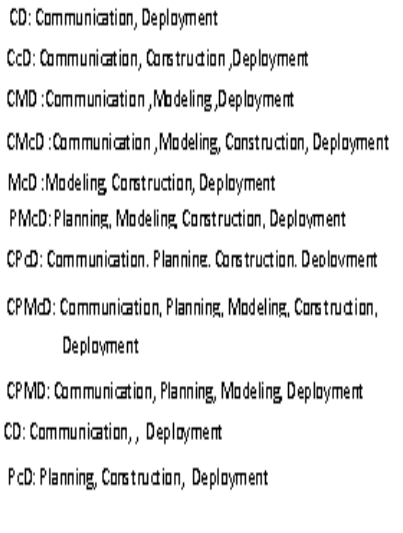 & 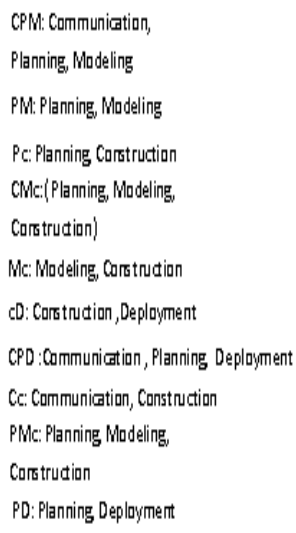 \\
\hline
\end{tabular}

In this set theory diagram, Our universal set contains all the factors of McCall's ,Boehm's, dromey's and ISO .The overlapping of five Components of Rapid Application development (RAD ) Model with quality factors of McCall's, Boehm's ,dromey's and ISO is shown .In this diagram C denotes Communication, $\mathrm{P}$ denotes planning , $\mathrm{M}$ denotes Modeling, c denotes construction and D denotes development. As a result, we have find above mentioned relationship of quality factors with components of RAD model. functionality,Reliability,Portability,Usability,Integrity,Testabi lity,flexibility,Reusability,Interoperability,Human engineering and Understandability lies in $\mathrm{CPDcD}$ means all these factors lies in all five components of RAD Model. While efficiency and maintainability lies in CPMD means that these two factors lies in Communication ,modeling, planning and development components of RAD Model[1][5].

Table 20: Quality Criterions and RAD Model

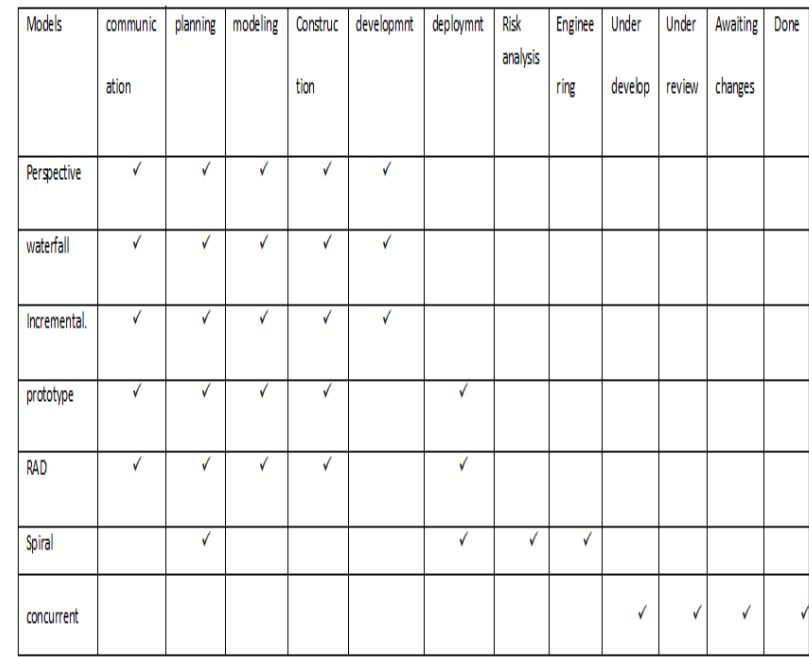

In Table 20 : the list of all Process Models and their respective Criterion is discussed. In Perspective Model Communication, Planning, Modeling, Construction and Development component are present .In Waterfall Model communication ,Modeling, Planning, construction and Development component are present. In Incremental process Model communication , Modeling, Planning, Construction and development components are present .In Prototype
Model, Communication, Modeling, Planning, Construction and deployment are present .In RAD Model communication, Modeling, Planning, Construction and Deployment are present. In Spiral Model Planning, Deployment, Risk Analysis and Engineering components are present. In Concurrent Development Model Under development, Under Review, Awaiting Changes and Done components are present. In Unified Process Model Inception( Communication, Planning),Elaboration( Planning ,Modeling) and Transition(Construction and Deployment ) components are present[1][5].

Table 21: MacCalls Quality Model and RAD Model

\begin{tabular}{|c|c|c|c|c|c|}
\hline Maccall's Ofactors & communization & plenning & Modeling & consiruction & deployment \\
\hline correctness & $\sqrt{ }$ & $\checkmark$ & $\sqrt{ }$ & $\checkmark$ & $\sqrt{ }$ \\
\hline Relibability & $\checkmark$ & $\checkmark$ & $\sqrt{ }$ & $\sqrt{ }$ & $\sqrt{ }$ \\
\hline Efficency & $\sqrt{\prime}$ & $\checkmark$ & 7 & & $\sqrt{\prime}$ \\
\hline Interitity & r & $\checkmark$ & r & $\checkmark$ & v \\
\hline Usiblilty & $\checkmark$ & $r$ & $r$ & $r$ & $\sqrt{r}$ \\
\hline Maintainability & $\sqrt{ }$ & $\checkmark$ & $\sqrt{ }$ & & $\checkmark$ \\
\hline Testability & $\checkmark$ & $\checkmark$ & $\sqrt{r}$ & $\checkmark$ & $\sqrt{ }$ \\
\hline Flexibility & $\checkmark$ & $\checkmark$ & r & $\checkmark$ & $\checkmark$ \\
\hline Portability & $r$ & $\checkmark$ & $r$ & $r$ & v \\
\hline Reubbility & $\checkmark$ & $r$ & $\checkmark$ & $\gamma$ & $\checkmark$ \\
\hline
\end{tabular}

In table 21: the list of all factors of McCall Quality Model and also their Occurrence in five component i.e Communication ,Planning, Modeling, and deployment component of Rapid Application Model (RAD) Model is discussed .The first factor Correctness is found in Communication, Modeling, Planning ,Construction and Deployment .The Second factor Reliability is found in Communication, Modeling, Planning ,Construction and Deployment component of Rapid Application Model (RAD) Model .The third factor Efficiency is found in Communication, Modeling, Planning and Deployment component of Rapid Aplication Model (RAD) Model. The fourth factor Integrity is found in Communication, Modeling, Planning, Construction and Deployment component of Rapid Application Model (RAD) model. The fifth factor Usability is found in Communication, Modeling, Planning, Construction and Deployment Component of Rapid Application Model (RAD) Model. The sixth factor Maintainability $\mathrm{s}$ found in Communication, Planning, Modeling and deployment component of RAD Model. The seventh factor Testability is found in Communication, Planning, Modeling, Construction and Deployment component of RAD Model. The eighth factor flexibility is found in Communication, Modeling, Planning, Construction and deployment factor of RAD Model .The ninth factor Portability is found in communication, Modeling , Planning, Construction and Deployment component of RAD Model. the tenth factor Reusability is found in communication, Modeling , Planning, Construction and Development of RAD Model[1][5]. 
Table 22: Boehm Quality Model and RAD Model

\begin{tabular}{|c|c|c|c|c|c|}
\hline 'Boetm's Qfifactors & communiction & Nodeling & plaming & consrution & deployment \\
\hline portadility & V & $\sqrt{ }$ & $\checkmark$ & $\sqrt{ }$ & $\sqrt{ }$ \\
\hline relibality & $\sqrt{ }$ & V & $\sqrt{ }$ & $\sqrt{ }$ & $\sqrt{ }$ \\
\hline efficency & $\checkmark$ & $\checkmark$ & $\checkmark$ & & $\checkmark$ \\
\hline Humban Enginerering & $\sqrt{ }$ & T & $\sqrt{ }$ & T & V \\
\hline Testability & $\checkmark$ & v & $\checkmark$ & $\checkmark$ & $\checkmark$ \\
\hline Undersiandobitity & $\checkmark$ & V & $\sqrt{ }$ & $\bar{v}$ & $\sqrt{ }$ \\
\hline
\end{tabular}

In table22: the list of all factors of Boehm's Quality Model and also their Occurrence in five component i.e Communication ,Planning ,Modeling , and Deployment component of Rapid Application Model (RAD) Model is discussed.The first factor Portability is found in Communication, Modeling, Planning ,Construction and Deployment components of RAD Model .The Second factor Reliability is found in Communication, Modeling, Planning ,Construction and Deployment component of RAD Model .The third factor Efficiency is found in Communication, Modeling, Planning and Deployment component of RAD Model. The fourth factor Human Engineering is found in Communication, Modeling, Planning, Construction and Deployment component of RAD Model. The fifth factor Testability is found in Communication, Modeling, Planning, Construction and Deployment Component of RAD Model. The sixth factor Understandability is found in Communication, Planning, Modeling and deployment component of RAD Model [1][5].

Table 23: Dromey Quality Model and RAD Model

\begin{tabular}{|c|c|c|c|c|c|}
\hline Dromey/s Qfotorors & communication & Modeling & Planing & Constution & Deploymerth \\
\hline \begin{tabular}{|l|} 
Functionality \\
\end{tabular} & $\checkmark$ & ل & V & V & $\sqrt{ }$ \\
\hline Relibility & r & r & $\checkmark$ & $\checkmark$ & r \\
\hline Minitzinability & 7 & r & $\gamma$ & & $\checkmark$ \\
\hline Efficienny & r & $\gamma$ & $\gamma$ & & r \\
\hline Revasibility & $\checkmark$ & $\gamma$ & $\gamma$ & $\checkmark$ & r \\
\hline | Portdility & $\checkmark$ & $\checkmark$ & $\gamma$ & v & v \\
\hline Usabilty & $r$ & r & r & r & $r$ \\
\hline
\end{tabular}

In table 23: the list of all factors of Dromey's Quality Model and also their Occurrence in five component i.e Communication ,Planning ,Modeling, construction and
Deployment component of Rapid Application Model (RAD) Model is discussed .The first factor Functionality is found in Communication, Modeling, Planning ,Construction and Deployment .The Second factor Reliability is found in Communication, Modeling, Planning ,Construction and Deployment component of RAD Model .The third factor Maintainability is found in Communication, Modeling, Planning and Deployment component of RAD Model. The fourth factor Efficiency is found in Communication, Modeling, Planning and Deployment component of RAD Model. The fifth factor Reusability is found in Communication, Modeling, Planning, Construction and Deployment Component of RAD Model. The sixth factor portability is found in Communication, Planning, Modeling and deployment component of RAD Model .The seventh factors Usability is found in Communication, Planning, Modeling,Construction and Deployment Component of RAD Model[1][5]

Table 24: ISO Quality Model and RAD Model

\begin{tabular}{|c|c|c|c|c|c|}
\hline 100 affitors & Communiction & Nodeling & Plaming & Constrution & Deplogment \\
\hline \begin{tabular}{|l|l} 
Functionality \\
\end{tabular} & v & v & V & v & v \\
\hline Relibality & $\checkmark$ & $\checkmark$ & $\checkmark$ & $\checkmark$ & $\checkmark$ \\
\hline \begin{tabular}{|l|l|l} 
Usbolly \\
\end{tabular} & v & l & V & v & v \\
\hline Efficency & v & V & V & & V \\
\hline Maintannobility & v & $\checkmark$ & $\checkmark$ & & $\checkmark$ \\
\hline \begin{tabular}{|l|} 
Portability \\
\end{tabular} & $\bar{v}$ & r & V & v & v \\
\hline
\end{tabular}

In table 24: the list of all factors of ISO Quality Model and also their Occurrence in five component i.e Communication, Planning, Modeling ,Construction and deployment component of Rapid Application Model (RAD) Model is discussed .The first factor Functionality is found in Communication, Modeling, Planning ,Construction and Deployment .The Second factor Reliability is found in Communication, Modeling, Planning ,Construction and Deployment component of RAD Model. The third factor Usability is found in Communication, Modeling, Planning and Deployment component of RAD Model. The fourth factor Efficiency is found in Communication, Modeling, Planning and Deployment component of RAD Model. The fifth factor Maintainability is found in Communication, Modeling, Planning and Deployment Component of RAD Model. The sixth factor portability is found in Communication, Planning, Modeling and deployment component of RAD Model [1][5].

\section{CONCLUSION}

The attempt of relating Quality Models with Process Models has shown a strong bonding relationship. The Factors, there criterion of Quality Models and the attributes of Process Models have synchronized with each other, resulting in similarity of their properties. By this synchronization the users of software quality insurance can have a wider pitch to justify the development, reliability and implementation of software. 
Along with this the enhancement of this work can end up to new quality model which can be justified by the process models. As we all know that designing software, the most important thing is to follow up its process properly.

\section{REFERENCES}

[1] Neumann W. Lawrence, Social Research Methods: Qualitative and Quantitative Approaches, Allyn and Bacon, 2000, p.558.

[2] Pressman S. Roger, Software Engineering: A Practitioner's Approach, McGraw-Hill Education, 2010,p.895.
[3] Brown Peter, E.Michael, H.David, M.Janine, P.Bill, R.Jacqui, Sets and Venn Diagrams, Australian Mathematical Sciences Institute, 2011, p.25.

[4] Kanamori Akihiro,The Mathematical Development of Set Theory from Cantor to Cohen, Association for Symbolic Logic,vol.2,1996,p.71.

[5] Basit Habib and Rana Aamir Raza Ashfaq. Article: Relationship between Factors of Quality Models and the System Development Life Cycle. International Journal of Computer Applications 81(10):39-44, November 2013 